
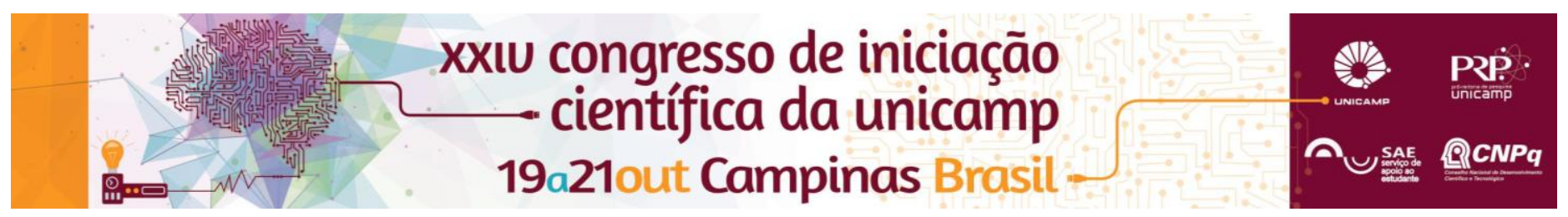

\title{
Trabalho infantil em Limeira - SP: Estratégias de proteção através do aplicativo mobile.
}

\author{
Anna Oliveira (IC), Amanda Morais (IC), Erick Sasse Filho (PQ), Eugênio Cassaro Filho(PQ), Isabela Silva (IC), \\ Luiz Garcia (IC), Márcia Vendramin (PQ), Marta Fuentes-Rojas (PQ), Michelly Oliveira (IC), Miriã Bolelho (IC), \\ Sandra F. B. Gemma (PQ), Sara Rodrigues (IC), Suelen Andrade* (IC).
}

\begin{abstract}
Resumo
A presente pesquisa foi desenvolvida como estratégia de enfrentamento ao trabalho infantil na cidade de Limeira - SP. O trabalho infantil se apresenta enquanto um fato social trazendo diversos efeitos (diretos e indiretos) sob os indivíduos que vivem nesta situação. A partir desse ponto, um aplicativo mobile foi desenvolvido na plataforma Android para que informações a esse respeito possam ser divulgadas aos cidadãos da cidade, visando uma melhoria na conscientização geral sobre este fenômeno, a oferta de recursos para denúncias e caminhos alternativos às situações de trabalho infantil.
\end{abstract}

\section{Palavras-chave:}

Trabalho infantil, Limeira, aplicativo.

\section{Introdução}

O trabalho infantil é caracterizado como qualquer forma de atividade realizada abaixo da idade mínima legal' ${ }^{1}$. O Brasil considera trabalho infantil aquele realizado em idade inferior a 14 anos, sendo que a faixa etária entre 14 a 18 anos é considerada para trabalho de menor aprendiz, desde que desenvolvido com supervisão e não expondo o jovem a riscos, funções insalubres ou que atrapalhem seu desenvolvimento físico ou intelectual ${ }^{1}$.

A OIT caracteriza as piores formas de trabalho, dentre as quais destacamos: exploração sexual comercial, tráfico de drogas, aliciamento ao crime, mendicância, trabalho em meio rural e doméstico ${ }^{2}$. Como efeito direto destas violações, encontramos um déficit no desenvolvimento físico, psíquico e social de crianças e adolescentes ${ }^{3}$.

A cidade de Limeira - SP, assim como diversas outras no país, apresenta demandas de proteção social nesta área e em uma pesquisa ${ }^{4}$ realizada no ano de 2005 constatou que $27 \%$ dos estudantes (8.340 indivíduos) realizavam trabalhos com semijoias e bijuterias dentro dos domicílios, situação esta considerada como de trabalho infantil. A principal atividade desenvolvida estava relacionada com montagem e soldagem.

Diante destas informações, a pesquisa-ação ${ }^{5}$ realizada teve como objetivo central desenvolver uma estratégia de enfrentamento do fenômeno em escala local, de forma a conscientizar pessoas que se encontram em situação de trabalho infantil direta ou indiretamente, contextualizando seus efeitos e direcionando encaminhamentos para agentes do sistema de proteção local.

\section{Resultados e Discussão}

A partir dos dados identificados a pesquisa propôs-se a formular uma maneira alternativa de divulgação do Sistema de Garantias de Direitos entre crianças e adolescentes. A informação a ser comunicada deverá conter três princípios básicos: ser capaz de circular dentro do maior número de casas (capilaridade da informação), passar segurança para garantir autonomia (sigilo da informação) e que não fosse percebida como algo aversivo ou desgastante (sentido da informação). Nesta direção foi pensado que um aplicativo de celular de interesse social cumpriria esta função. Após pesquisa descobrimos que a maior plataforma mobile no Brasil é a Android e como ferramentas neste desenvolvimento, foram utilizados os software Android Studio (programação básica) e Atom (edição de texto específico para base de dados) para incorporar as informações e alguns comandos básicos.

A partir daí iniciou-se uma série de tarefas em pesquisa: 1) levantamento bibliográfico sobre trabalho infantil; 2) estudos sobre o sistema de proteção social que incorpora este fenômeno; 3) diagnóstico dos equipamentos e serviços sociais de suporte para a demanda de trabalho infantil; 4) desenvolvimento do design do software (cores, logotipo e caracteres); 5) menus e desdobramentos; 6) estratégias de divulgação. O aplicativo Trabalho Infantil Limeira (TIL) apresenta três menus iniciais:

1: O que é trabalho infantil: Referências e definições do trabalho infantil. Perguntas e repostas sobre o tema.

2: Preciso de Ajuda: Quiz interativo com 10 questões que, ao final, apresentam alguns possíveis encaminhamentos, em um formato personalizado conforme o diálogo com o respondente.

3: Sugestões: Apresenta a rede de serviços que atuam sob algumas dimensões de enfrentamento ao trabalho infantil como: Cultura, Educação, Esporte, Profissionalização e Proteção Social.

A divulgação do aplicativo se dará em parceria com a COMETIL e escolas da cidade.

\section{Conclusões}

Através do aplicativo espera-se que a ferramenta seja capaz de favorecer o atendimento à questão in loco através do diálogo direto com o público-alvo: crianças e adolescentes, possibilitando assim a garantia de seu lugar de sujeitos (não de objetos) nas políticas públicas.

\section{Agradecimentos}

Ao PIBIC, FCA, alunos, monitores e professores que tornaram esta conquista possível. 